\title{
Gridshell em madeira: aspectos teóricos e construtivos
}

Wood gridshell: theoretical and constructive aspects

\begin{tabular}{|c|c|}
\hline & $\begin{array}{l}\text { J ulio Cesar Molina } \\
\text { Carlito Calil Neto } \\
\text { Anderson Diego da Fé } \\
\text { Ulysses Martins Freitas } \\
\text { Pablo Henrique de Morais } \\
\text { Gabriela da Silva Matos }\end{array}$ \\
\hline $\begin{array}{r}\text { 1J ulio Cesar Molina } \\
{ }^{1} \text { Universidade Estadual Paulista } \\
\text { Itapeva - SP - Brasil }\end{array}$ & $\begin{array}{l}\text { Resumo } \\
\text { s gridshells são estruturas leves, que permitem a obtenção de } \\
\text { grandes vãos livres, além de uma ampla variedade de formas } \\
\text { arquitetônicas. No entanto, no Brasil, não existem registros da } \\
\text { construção desse tipo de estrutura (em caráter permanente) nem }\end{array}$ \\
\hline $\begin{array}{r}{ }^{2} \text { Rewood - Soluções Estruturais em } \\
\text { Madeira Laminada Colada } \\
\text { Taboão da Serra - SP - Brasil }\end{array}$ & $\begin{array}{l}\text { Palavras-chave: Gridshell em madeira. Estrutura reticulada. Metodologia construtiva. } \\
\text { Abstract }\end{array}$ \\
\hline $\begin{array}{r}{ }^{3} \text { Anderson Diego da Fé } \\
{ }^{3} \text { Universidade Estadual Paulista } \\
\text { Guaratinguetá - SP - Brasil }\end{array}$ & $\begin{array}{l}\text { Gridshells are light structures that allow the obtention of large spans, as well } \\
\text { as the use of a wide variety of architectural shapes. However, in Brazil, there } \\
\text { are no records of the construction of this type of structure, neither literature } \\
\text { available on this type of structural composition. This paper presents the main }\end{array}$ \\
\hline $\begin{array}{r}{ }^{4} \text { Ulysses Martins Freitas } \\
\text { 4Universidade Estadual Paulista } \\
\text { Itapeva - SP - Brasil }\end{array}$ & $\begin{array}{l}\text { theoretical aspects, as well as design and construction details of a gridshell } \\
\text { built in wood in real scale. The construction costs are also reported. The } \\
\text { structure was built by using a quadrangular flat mesh configuration, formed }\end{array}$ \\
\hline $\begin{array}{r}{ }^{5} \text { Pablo Henrique de Morais } \\
\text { 5Universidade Estadual Paulista } \\
\text { Itapeva - SP - Brasil }\end{array}$ & $\begin{array}{l}\text { mm diameter screws. The plane mesh (with total dimensions of } 9 \mathrm{~m} \times 9 \mathrm{~m} \text { ) was } \\
\text { bent until the desired curve was achieved. The system was subsequently locked } \\
\text { by diagonal bracing elements. The knowledge obtained through this practical } \\
\text { application led to a significant improvement in the original design idea related } \\
\text { to controlling the shape of the structure during the building phase and the the } \\
\text { optimisation of the executing strategies. The building recommendations } \\
\text { presented in this paper will be a contribution to the scarce literature on the } \\
\text { subject currently available in Brazil. }\end{array}$ \\
\hline & s: Wood gridshell. Reticulated structure. Constructive methodology. \\
\hline
\end{tabular}

MOLINA, J. C.; CALIL NETO, C.; FÉ, A. D. da; FREITAS, U. M.; MORAIS, P. H. de; MATOS, G. da S. Gridshell em madeira: 277 aspectos teóricos e construtivos. Ambiente Construído, Porto Alegre, v. 20, n. 1, p. 277-295, jan./ mar. 2020. ISSN 1678-8621 Associação Nacional de Tecnologia do Ambiente Construído. http:// dx. doi. org/ 10.1590/ s1678-86212020000100374 


\section{Introdução}

Gridshells são estruturas tridimensionais, não planas, que se assemelham às cúpulas geodésicas, mas que permitem maior liberdade de curvatura de forma geral. Permitem formas cilíndricas, elípticas, hiperbólicas, entre outras (GHIYASINASAB; LEHOUX; MÉNARD, 2017) e, sobretudo, a cobertura de grandes áreas sem a necessidade de apoios intermediários, tirando maior proveito do comportamento estrutural tridimensional para atingir metas arquitetônicas. Quando a forma geométrica curva da gridshell é obtida por meio do envergamento dos seus elementos retilíneos, tem-se uma classificação referente ao processo construtivo denominada "pós-formada". Se a forma curva da gridshell é obtida a partir do uso de peças pré-fabricadas, a estrutura é classificada como "pré-formada" (CAFFARELLO; MASCIA; BASAGLIA, 2016). A madeira consiste em uma excelente opção de material para a construção das gridshells (KUNS; PRAUCHNER, 2015). Dentre as vantagens da madeira para esse tipo de estrutura está a leveza (peso próprio entre $70 \mathrm{~N} / \mathrm{m}^{2}$ e $20 \mathrm{~N} / \mathrm{m}^{2}$ (MESNIL, 2013)). Dentre as espécies de madeiras brasileiras com potencial para a construção das gridshells estão as madeiras de reflorestamento como os pínus e os eucaliptos. A maioria das gridshells construídas até o momento em outros países basicamente utiliza madeiras do tipo coníferas. No caso das gridshells, tem-se basicamente uma estrutura reticulada (formada por elementos de barras), cuja malha que forma a superfície pode ser projetada a partir de diferentes configurações de forma como, por exemplo, a quadrangular e a triangular. De acordo com Harris et al. (2003) e Seifi et al. (2018), a união entre os elementos de barra na formação da malha geralmente é feita por parafusos, embora outros tipos de conetores projetados para tal finalidade possam ser utilizados. Por outro lado, nem sempre a eficiência da geometria das gridshells se traduz em eficiência orçamental. Sendo assim, apesar do seu potencial, as gridshells muitas vezes são limitadas na sua utilização a projetos de alto nível, com grandes orçamentos. Existe ainda a relativa complexidade de projeto e de cálculo que desencoraja os projetistas por sua escolha (SAKAI; OHSAKI, 2018). No entanto, atualmente, com o desenvolvimento da informática, estudos de caráter numérico, a partir do uso softwares específicos, têm ocorrido com maior frequência, o que facilita o entendimento do seu comportamento estrutural e contribui para o seu procedimento de cálculo.

A primeira gridshell que se tem conhecimento no mundo foi construída em aço, na Rússia, em 1896. Mais tarde, a primeira gridshell em madeira foi construída na Alemanha, em 1975 (TOUSSAINT, 2007). Também existem relatos da construção de gridshells em madeira na Inglaterra e na Itália, e registros mais recentes em Portugal (CARVALHO, 2015), na França, na Espanha, na Argentina, como também na Romênia. Lamentavelmente, não existem no Brasil registros da construção de gridshells em madeira em caráter definitivo. Além disso, a literatura sobre esse tema no país é escassa e os trabalhos publicados até o momento têm cunho numérico (CAFFARELLO; MASCIA; BASAGLIA, 2016) ou fazem uma revisão de literatura com base em trabalhos estrangeiros (KUNZ; PRAUCHNER, 2015). Alguns registros da construção de gridshells no Brasil consideram estruturas provisórias, para fins demonstrativos na área de arquitetura. Estudos envolvendo a construção de uma gridshell com madeiras de pínus também têm sido desenvolvidos pelo LABEM na UFRN (AGÊNCIA..., 2018).

O presente trabalho teve como objetivo inicial o desenvolvimento de uma revisão de literatura voltada ao entendimento teórico do comportamento das gridshells em madeira. Posteriormente, como uma aplicação prática, foi construída uma estrutura de cobertura do tipo gridshell, em escala real e em caráter definitivo, a partir da utilização de madeiras de reflorestamento (folhosas) para entendimento e otimização das etapas construtivas.

\section{Teoria de cascas}

As cascas são estruturas contínuas de superfície, não planas, de pequena espessura, que absorvem as cargas externas por esforços, predominantemente de compressão, no plano da superfície. Quando se estudam os elementos de barra para fins de análise estrutural, a geometria é representada pelo eixo. No caso das cascas, utiliza-se a superfície média e, consequentemente, os esforços atuantes são de superfície. Sabe-se também que a rigidez à flexão por unidade de largura é proporcional ao momento de inércia $\left(\mathrm{I}=\mathrm{b} \cdot \mathrm{h}^{3} / 12\right.$, sendo $\mathrm{b}$ e $\mathrm{h}$ a largura e a altura da seção transversal do elemento de casca, respectivamente). Assim, como a altura no caso das cascas é pequena, isso resulta em um elemento elevado à terceira potência muito pequeno, e, neste caso, adota-se $\mathrm{I} \approx 0$. Portanto, a teoria de cascas parte da hipótese que $\mathrm{I}=0$. Além disso, como o momento fletor (M) é proporcional ao momento de inércia (I), adota-se $\mathrm{M}=0(\mathrm{M}=\sigma . \mathrm{I} / \mathrm{y}$, sendo $\sigma$ a tensão normal na seção e y a distância da linha neutra até o ponto onde se quer calcular a tensão) na teoria de cascas, desprezando-se assim a rigidez à flexão como boa aproximação. Por outro lado, a pequena rigidez do elemento isolado não implica pequena rigidez do conjunto que, devido à sua forma, pode resistir aos esforços de compressão sem 
risco de flambagem. O conjunto de superfície curva tem grande rigidez quando comparado com a mesma superfície plana. Vale dizer ainda que as reações das cascas esféricas nos apoios devem ter direção tangente à superfície no ponto. Quando isso não acontece, são geradas perturbações nas bordas das cascas dando origem a esforços de flexão nas regiões próximas às bordas.

\section{Comportamento estrutural de uma gridshell}

A definição de gridshell sugere que o sistema trabalhe como uma estrutura de casca (KUNZ; PRAUCHNER, 2015). Assim, se a malha da gridshell for admitida como contínua, uma carga distribuída vertical na estrutura de casca resulta em esforços de compressão e de cisalhamento (Figura 1a). Esse mecanismo cria um sistema rígido em que cada elemento quadrangular de superfície contínua da malha é bloqueado por esforços internos e os transfere para os elementos vizinhos. O comportamento da malha, neste caso, faz com que todas as cargas sejam transferidas para as bordas externas do elemento quadrangular, o qual pode transmitir somente forças de compressão na direção das barras (Figura 1b). Dessa forma, não há necessidade de superfícies espessas ou de elevada inércia para resistir a tais esforços. Ao se introduzir um elemento diagonal na malha (Figura 1c), uma rigidez passa a existir e as forças de cisalhamento que surgem são transmitidas para as bordas do elemento quadrangular, fazendo com que esse elemento trabalhe como uma malha contínua. Assim, nas gridshells, os esforços são transmitidos para o elemento quadrangular vizinho (TOUSSAINT, 2007). A Figura 1 mostra os esforços em função da configuração da malha quadrangular para uma gridshell.

\section{Curvatura máxima de um elemento de barra na flexão}

A capacidade última de curvatura de um elemento de barra depende do momento resistente, que, por sua vez, é dependente da tensão última do material da barra. Portanto, os elementos de barra que compõem o sistema podem ser dobrados até atingirem uma curvatura em que o nível final de resistência à flexão ( $\mathrm{f}_{\mathrm{M}}$ ) para $\mathrm{o}$ material é atingido. O momento devido à curvatura é calculado pela Equação 1 e a tensão normal devido à flexão $\left(\sigma_{M}\right)$, nas fibras mais externas do elemento, é dada pela Equação 2. Substituindo-se a equação (1) em (2) e admitindo-se a tensão de flexão $\left(\sigma_{M}\right)$ como a resistência de flexão $\left(\mathrm{f}_{\mathrm{M}}\right)$, obtém-se o valor do raio máximo $\left(\mathrm{R}_{\max }\right)$ a ser admitido na flexão de um elemento de barra, conforme a Equação 3. Considerando-se a madeira como o material em questão, observa-se que o raio máximo de curvatura depende da resistência de flexão e do módulo de elasticidade. Segundo Toussaint (2007), quando uma grande curvatura é desejada deve-se selecionar uma espécie de madeira com pequena relação $\mathrm{E}_{\mathrm{M}} / \mathrm{f}_{\mathrm{M}}$. Como uma estimativa simplificada, o autor recomenda ainda a Equação 4, que considera um raio mínimo $\left(\mathrm{R}_{\mathrm{m}}\right)$. Além disso, segundo o mesmo autor, na construção de gridshells, madeiras com classe de resistência acima de C40 devem ser evitadas. A Figura 2 mostra a seção transversal típica considerada para o elemento de uma gridshell.

Toussaint (2007) apresenta expressões para o raio mínimo $\left(\mathrm{R}_{\mathrm{m}}\right)$ em função das classes de resistência da madeira. Para coníferas (C30 e C40) recomenda $R_{m}=200$.d e $R_{m}=175$.d, respectivamente (sendo $d=2 . z$ ). Para folhosas (D30 e D40) $R_{m}=167$.d e $R_{m}=138$.d, respectivamente. Como regra geral, recomenda $R_{m}=$ 200.d para coníferas e $R_{m}=145$.d para folhosas. Por outro lado, sabe-se que o raio de flexão (R) depende do ângulo de curvatura $\theta$ do elemento de barra e do comprimento do arco s, conforme Equações 5 e 6 , sendo $\mathrm{r}$ a metade da distância horizontal formada pelo arco completo. A Figura 3 apresenta os parâmetros necessários para a determinação do raio $\mathrm{R}$ para um segmento de arco.

Figura 1 - Esforços internos: (a) Elemento continuo de casca; (b) Elemento quadrangular de grelha; (c) Elemento quadrangular de grelha com diagonal

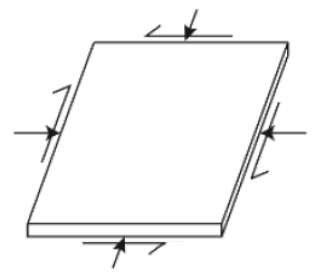

(a)

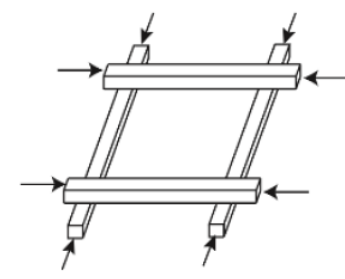

(b)

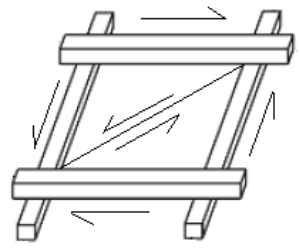

(c)

Fonte: modificado de Toussaint (2007). 
Figura 2 - Seção típica de uma gridshell com ripas duplas

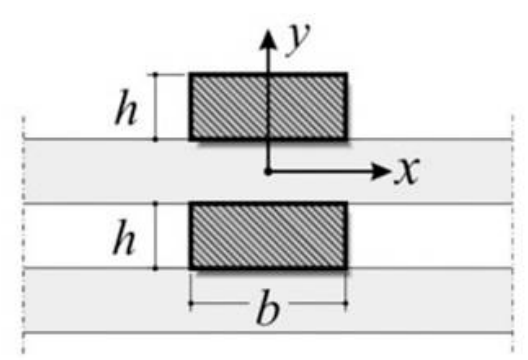

$$
M=E_{M} \times I \times k \quad \text { Eq. }
$$

1

$$
R_{\max }=\frac{E_{M} \times h}{2 \times f_{M}} \quad \text { Eq. } 3
$$$$
R_{m}=z \times \frac{E_{M}}{f_{M}} \quad \text { Eq. } 4
$$

Fonte: D'Amico et al. (2015).

Nota: Legenda:

$$
\begin{aligned}
& \text { I = momento de inércia da seção; } \\
& \text { k =curvatura do elemento (1/R); } M=\text { momento fletor do elemento; } \\
& E_{M}=\text { módulo de elasticidade da madeira na flexão; } \\
& b=\text { largura da seção transversal; } h=\text { altura da seção transversal; } \\
& W=\text { ó́dulo de resistência da seção }\left(b . h^{2} / 6\right) ; \text { e } \\
& z=\text { distância do eixo central considerado para o elemento até a fibra mais afastada. }
\end{aligned}
$$

Figura 3 - Segmento de arco

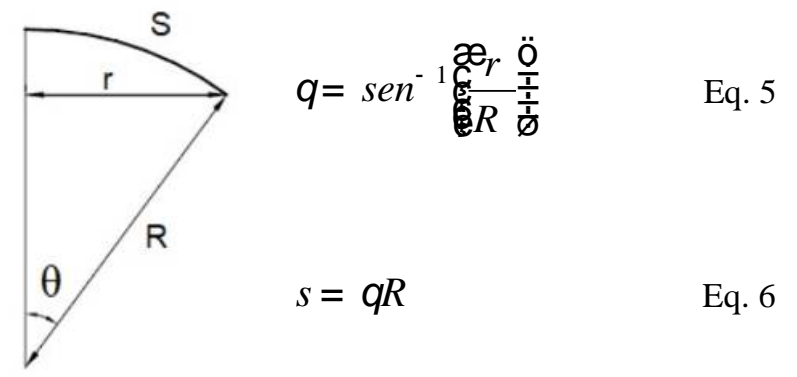

Fonte: modificado de Toussaint (2007).

Para a verificação da falha por flexão, o documento normativo Eurocode 5 (EUROPEAN..., 2008) considera um fator de correção $\mathrm{k}_{\mathrm{r}}$, o qual considera a redução das tensões de flexão devido à relaxação do material componente do elemento de barra. Segundo Harris et al. (2003), a relaxação reduz as tensões de flexão geradas pela flexão inicial dos elementos durante o processo de deformação. Dessa forma, a condição de falha por flexão de um elemento de barra é verificada pela Equação 7, a qual é complementada pela Equação 8, tendo como base a Figura 4. Para fins de projeto, o valor de cálculo da resistência de flexão (f $\left.f_{M d}\right)$ deve ser usado de acordo com a Equação 9, admitindo-se, neste caso, a aplicação de uma carga de média duração. Um método de relaxação dinâmica para a verificação dos elementos de barra de uma gridshell em madeira também é proposto por D’Amico et al. (2015).

$S_{M, d}=k_{r} \times f_{M, d}$

$k_{r}=\begin{array}{ll}1 & \text { se }\left(R_{\text {in }} / t\right)^{3} 240 \\ 0.76+0.001 \times\left(R_{\text {in }} / t\right) & \text { se }\left(R_{\text {in }} / t\right)<240\end{array}$

Eq. 8

Onde:

$\sigma_{\mathrm{Md}}=$ valor de cálculo da tensão de flexão;

$\mathrm{f}_{\mathrm{Md}}=$ valor de cálculo da resistência à flexão;

$\mathrm{t}=$ espessura do elemento de barra; $\mathrm{e}$

$\mathrm{R}_{\mathrm{in}}=$ raio interno de curvatura do elemento. 


$$
f_{M, d}=\frac{k_{\mathrm{mod}} \times f_{M, k}}{g_{w}}
$$

Onde:

$\mathrm{k}_{\mathrm{mod}}=$ coeficiente de modificação para a madeira;

$\mathrm{f}_{\mathrm{M}, \mathrm{k}}=$ valor característico da resistência à flexão do elemento; e

$\gamma_{\mathrm{w}}=$ coeficiente de ponderação das resistências.

$\mathrm{O}$ valor de cálculo da tensão de flexão $\left(\sigma_{\mathrm{M}, \mathrm{d}}\right)$, segundo a Equação 7 , é obtido pela Equação 10 , sendo os coeficientes necessários para o cálculo do fator $\mathrm{k}_{1}$ dados pela Equação 11, onde: $\mathrm{k}_{1}=1,00 ; \mathrm{k}_{2}=0,35 ; \mathrm{k}_{3}=0,6$ e $\mathrm{k}_{4}=6,00$.

$$
\begin{aligned}
& s_{M, d}=k_{l} \frac{6 \times M_{a p, d}}{b \times h_{a p}{ }^{2}}
\end{aligned}
$$

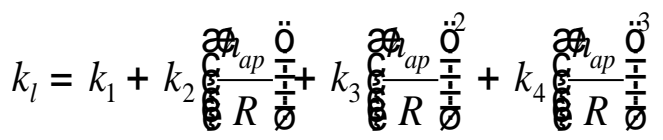

Onde:

$\sigma_{\mathrm{Md}}=$ valor de cálculo da tensão de flexão;

$\mathrm{M}_{\mathrm{ap}, \mathrm{d}}=$ valor de cálculo do momento na região do ápice (hachurada na Figura 4);

$h_{\mathrm{ap}}=$ altura da seção na região do ápice; e

b = largura da seção.

Em uma gridshell, o efeito de uma distribuição de tensão não linear está presente devido à forte curvatura na combinação das tensões de flexão. Segundo Toussaint (2007), o fator kl é aplicado para quantificar esse efeito. Em um trecho curvo (Figura 4a), a distribuição das tensões de flexão na seção transversal do elemento de barra, com base na teoria da elasticidade de Navier, é não linear (Figura 4b). Assim, no trecho curvo, tendo como base a lei de Hooke, a tensão nas fibras externas $\left(\sigma_{0}\right)$ é menor que a tensão nas fibras internas $\left(\sigma_{\mathrm{i}}\right)$. Para recuperar o equilíbrio das forças, a linha neutra da seção (LN) tem que se deslocar para baixo.

Figura 4 - Elemento de barra da gridshell: (a) Trecho curvo do elemento; (b) Distribuição das tensões na seção do elemento curvo

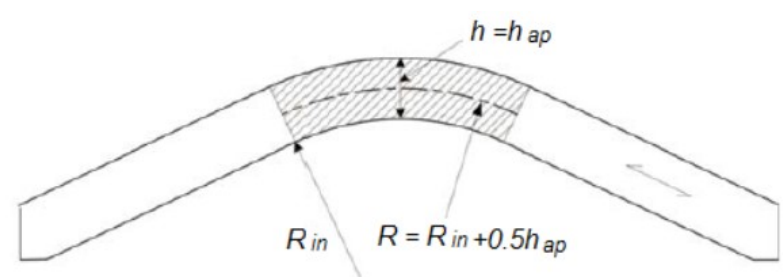

(a)

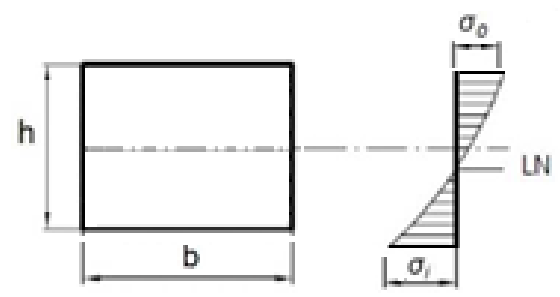

(b)

Fontes: (a) Eurocode 5 (EUROPEAN..., 2008) e (b) modificado de Blass et al. (1995). 


\section{Torção}

A máxima tensão de torção ocorre na região central das bordas de um elemento. De acordo com o Eurocode 5 (2008), a falha por torção do elemento deve ser verificada pela Equação 12, que considera um fator de forma $\mathrm{k}_{\text {shape }}$ aplicado à resistência ao cisalhamento do elemento, conforme Equação 13.

$$
\begin{aligned}
& t_{\text {tor }, d}=k_{\text {shape }} \times f_{v, d} \\
& k_{\text {shape }}=\min \left\{\begin{array}{l}
1+0.15 \times(\mathrm{h} / \mathrm{b}) \\
2.0
\end{array}\right.
\end{aligned}
$$

Onde:

$\tau_{\text {tor,d }}=$ valor de cálculo da tensão de torção;

$\mathrm{f}_{\mathrm{vd}}=$ valor de cálculo da resistência de cisalhamento;

$\mathrm{k}_{\text {shape }}=$ valor que depende da forma da seção;

b = largura da seção; e

h = altura da seção.

De acordo com Young e Budynas (2002), para uma seção retangular com b $\geq \mathrm{h}$ (Figura 4b), a tensão máxima de torção que ocorre nas bordas da parte central do elemento de barra pode ser calculada pela Equação 14. As Equações 15 e 16 complementam a Equação 14.

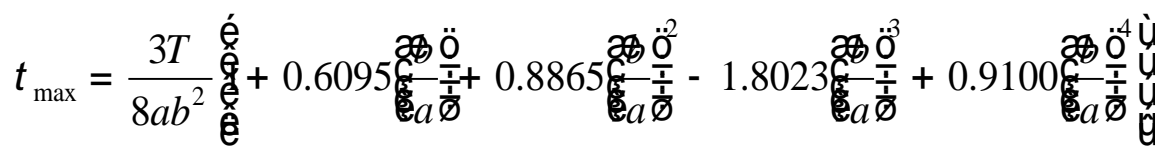

$T=\frac{K \cdot G \cdot q_{t}}{l}$

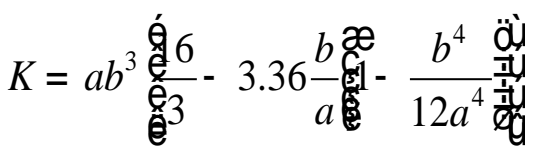

Eq. 16

Onde:

$\tau_{\max }=$ tensão máxima de torção;

$\mathrm{T}=$ momento de torção;

$\mathrm{a}=\mathrm{b} / 2$ (Figura 4b);

$\mathrm{h}=\mathrm{b} / 2$ (Figura $4 \mathrm{~b}$ );

$\mathrm{l}$ = comprimento do elemento de barra;

$\mathrm{G}$ = módulo de cisalhamento; e

$\theta_{\mathrm{t}}=$ ângulo de torção.

Para fins de projeto, o valor de cálculo da resistência ao cisalhamento $\left(\mathrm{f}_{\mathrm{v}, \mathrm{d}}\right)$ deve ser usado de acordo com a Equação 17, conforme Eurocode 5 (EUROPEAN..., 2008).

$f_{v, d}=\frac{k_{\mathrm{mod}} \times f_{v, k}}{g_{w}}$

Onde:

$\mathrm{k}_{\text {mod }}=$ coeficiente de modificação que considera a classe de carregamento, a umidade da madeira e se a madeira é ou não classificada mecânica e/ou visualmente;

$\mathrm{f}_{\mathrm{v}, \mathrm{k}}=$ valor característico da resistência ao cisalhamento; e 
$\gamma_{\mathrm{w}}=$ coeficiente de ponderação da resistência.

\section{Combinação das tensões}

Quando a grade plana da gridshell é deformada para a obtenção da forma curva, os elementos de barra que compõem a malha são sujeitos a momentos de flexão em duas direções, torção e forças cortantes em duas direções. Essa deformação pode ser conduzida até a deformação última do sistema. Após a construção, ocorre o relaxamento da madeira. Assim, parte das tensões iniciais de flexão desaparecerá. Estima-se uma diminuição de até $50 \%$ com relação às tensões iniciais de flexão, permanecendo na estrutura a outra metade das tensões residuais (TOUSSAINT, 2007).

Para verificar a combinação de tensões que provocam a falha da estrutura na fase de construção é necessária a utilização de um critério que considere todas as combinações de tensões possíveis. No entanto, as diretrizes existem apenas para certas combinações de tensões. Para uma gridshell, atualmente, são utilizados os critérios de combinações existentes. De acordo com o Eurocode 5 (2008), o critério de combinação entre tensões de flexão com tensões de tração ou compressão em duas direções, no estado limite último, é dado pelas Equações 18 e 19:

$$
\begin{aligned}
& \frac{s_{\mathrm{c} / \mathrm{t}, 0, d}}{f_{\mathrm{c} / \mathrm{t}, 0, d}}+\frac{S_{M, \mathrm{y}, d}}{f_{M, y, d}}+k_{m} \frac{s_{M, z, d}}{f_{M, \mathrm{z}, d}} £ 1.0 \\
& \frac{\mathrm{s}_{\mathrm{c} / \mathrm{t}, 0, d}}{f_{\mathrm{c} / \mathrm{t}, 0, d}}+k_{m} \frac{s_{M, \mathrm{y}, d}}{f_{M, y, d}}+\frac{S_{M, \mathrm{z}, d}}{f_{M, \mathrm{z}, d}} £ 1.0
\end{aligned}
$$

Onde:

$\sigma_{\mathrm{c} / \mathrm{t}, 0, \mathrm{~d}}=$ valor de cálculo da tensão de compressão/tração na direção paralela às fibras;

$\mathrm{f}_{\mathrm{c} / \mathrm{t}, 0, \mathrm{~d}}=$ valor de cálculo da resistência de compressão/tração na direção paralela às fibras;

$\sigma_{\mathrm{M}, \mathrm{y} / \mathrm{z}, \mathrm{d}}=$ valor de cálculo da tensão de flexão na direção y ou z;

$\mathrm{f}_{\mathrm{M}, \mathrm{y} / \mathrm{z}, \mathrm{d}}=$ valor de cálculo da resistência à flexão na direção y ou z; e

$\mathrm{k}_{\mathrm{m}}$ = fator que considera a redistribuição das tensões e o efeito da não homogeneidade do material em uma seção transversal ( $\mathrm{k}_{\mathrm{m}}=0,7$ para seções retangulares de madeiras maciças).

O Eurocode 5 (2008) não apresenta recomendações para a combinação entre tensões de cisalhamento e torção. No entanto, pode ser admitida a Equação 20, complementada pelas Equações 21 e 22 para a combinação geral entre tensões normais, de flexão, torção e cisalhamento (TOUSSAINT, 2007):

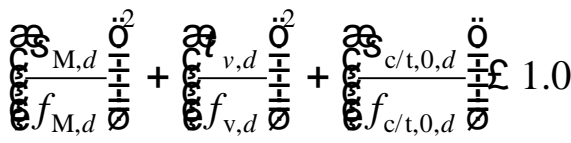

$$
\begin{aligned}
& S_{\mathrm{M}, d}=S_{\mathrm{M}, \mathrm{y}, d}+S_{\mathrm{M}, \mathrm{z}, d} \\
& t_{v, d}=t_{x y, d}+t_{t o r, d}
\end{aligned}
$$

Onde $\tau_{\mathrm{xy}, \mathrm{d}}$ é o valor de cálculo da tensão de cisalhamento.

\section{Processo construtivo: metodologia Modelo reduzido}

Para prever o comportamento da estrutura real durante a fase de montagem foi confeccionado um modelo reduzido, numa escala de 1:10. A configuração geométrica da malha da gridshell foi baseada no trabalho de D’Angelo (2011). A malha plana do modelo foi deformada até atingir a configuração tridimensional curva esperada. Para a deformação da malha foram aplicadas forças horizontais nas diagonais de apoio com $45^{\circ}$. Observou-se que as regiões centrais dos arcos de entrada apresentaram maior tendência de ruptura, devido à necessidade de maior curvatura para os elementos de barra. Essa tendência de ruptura dos arcos de entrada também foi relatada nas simulações numéricas desenvolvidas por Tedeschi (2018) em uma gridshell 
semelhante. A partir do modelo reduzido foi possível estimar as alturas das aberturas dos arcos de entrada, como também a altura do pé-direito da parte central curva da estrutura real. Portanto, a definição da forma arquitetônica tridimensional curva do modelo ocorreu por meio de uma sucessão de ações configurando uma metodologia operativa que foi definida, neste trabalho, como um método empírico da pesquisa de forma. Teoricamente, por se tratar de uma estrutura em forma de concha, as tensões atuantes nas gridshells são dependentes de sua forma geométrica. Assim, se a estrutura é submetida ao regime de compressão pura, os efeitos das tensões de flexão são evitados. Essa hipótese permaneceu como um ponto inicial de referência a partir do qual se iniciou a busca pela forma da estrutura (processo conhecido por form finding). A Figura 5 mostra os principais detalhes do modelo reduzido construído para o conhecimento preliminar dos desafios de montagem da estrutura real. Mostra ainda a distribuição das tensões máximas observadas por Tedeschi (2018) nos arcos de entrada de uma gridshell, semelhante ao modelo reduzido utilizado nesta pesquisa.

\section{Caracterização das madeiras utilizadas}

Na construção da malha da gridshell foram utilizadas madeiras de Lyptus (híbrido de Eucalyptus grandis e Eucalyptus urophylla). Nas demais partes da estrutura utilizou-se madeiras de Corymbia citriodora (colunas roliças de apoio) e Eucalyptus grandis (floreiras). A madeira de Lyptus foi escolhida por apresentar pouco empenamento como também poucas rachaduras e lascamentos. É uma madeira de média densidade e apresenta excelente trabalhabilidade no quesito usinagem. Todas as madeiras utilizadas passaram por processo de classificação mecânica com base na NBR 7190 (ABNT, 1997), e visual, com base nas recomendações de Calil Junior et al. (2019). A classificação visual buscou escolher as peças de madeira de melhor qualidade mediante identificação e eliminação dos defeitos próprios (presença de nós, inclinação de fibras, etc.), os quais reconhecidamente diminuem a resistência da madeira. A caracterização mecânica teve como objetivo a determinação das propriedades elásticas e de resistência das madeiras utilizadas. Considerou-se o teor de umidade (U) padrão de $12 \%$ na determinação das propriedades mecânicas das madeiras, conforme NBR 7190 (ABNT, 1997).

Os ensaios mecânicos foram realizados a partir da utilização da máquina universal de ensaios EMIC com capacidade para $300 \mathrm{kN}$. Utilizou-se um total de 12 replicações de amostras na caracterização de cada uma das propriedades da madeira. A Tabela 1 apresenta os resultados da caracterização mecânica das madeiras utilizadas na confecção da gridshell. A classe de resistência obtida para todas as madeiras caracterizadas foi C40. A classificação visual indicou madeiras de classes 1 e 2. Para a madeira de Lyptus, a relação obtida para o raio mínimo $\left(\mathrm{R}_{\mathrm{m}}\right)$ foi de $149,78 . d$, sendo relativamente superior ao valor propostos por Toussaint (2007) para dicotiledôneas $\left(\mathrm{R}_{\mathrm{m}}=145 . \mathrm{d}\right)$.

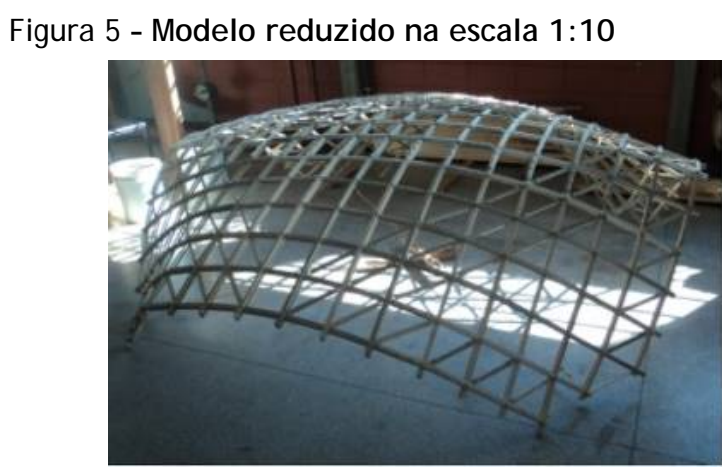

(a) Vista geral

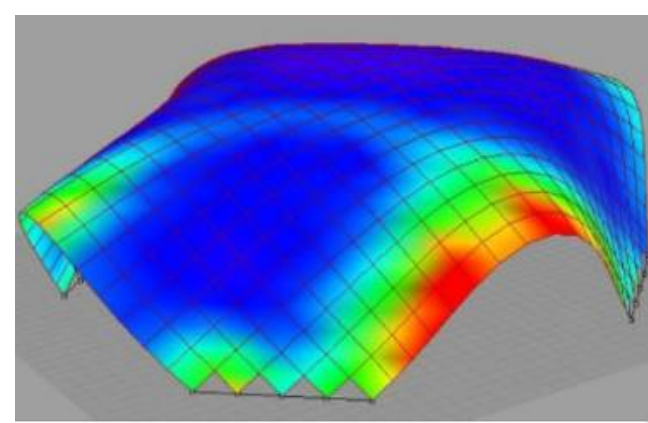

(b) Tensões máximas nos arcos de entrada verificadas por simulação computacional

Fonte: (b) Tedeschi (2018). 
Tabela 1 - Propriedades das madeiras utilizadas na gridshell ( $\mathrm{U}=\mathbf{1 2} \%$ )

\begin{tabular}{|c|c|c|c|c|c|c|c|c|}
\hline Madeira & $\begin{array}{c}\mathbf{f}_{\mathrm{c} 0, \mathrm{~m}} \\
(\mathrm{MPa})\end{array}$ & $\begin{array}{c}\mathbf{f}_{\mathrm{c} 90, \mathrm{~m}} \\
(\mathrm{MPa})\end{array}$ & $\begin{array}{c}\mathbf{f}_{\mathrm{v} 0, \mathrm{~m}} \\
(\mathrm{MPa}) \\
\end{array}$ & $\begin{array}{c}\text { Ec0,m } \\
\text { (MPa) }\end{array}$ & $\begin{array}{c}\mathbf{f}_{\mathrm{M} 0, \mathrm{~m}} \\
(\mathrm{MPa})\end{array}$ & $\begin{array}{c}\mathbf{f}_{\mathbf{t} 0, \mathrm{~m}} \\
(\mathrm{MPa})\end{array}$ & $\begin{array}{c}\text { EM0,m } \\
\text { (MPa) } \\
\end{array}$ & $\begin{array}{c}\begin{array}{c}\rho a p \\
\left(\mathrm{~kg} / \mathrm{m}^{3}\right)\end{array} \\
\end{array}$ \\
\hline Lyptus $^{\circledR}$ & 63,00 & 15,75 & 10,90 & 18504 & 111,19 & 81,90 & 16654 & 954 \\
\hline C. citriodora & 69,09 & 17,26 & 6,90 & 23918 & 121,94 & 89,72 & 19526 & 980 \\
\hline E. grandis & 58,30 & 12,09 & 6,90 & 11816 & 118,98 & 71,04 & 10645 & 650 \\
\hline
\end{tabular}

Nota: Legenda:

$\mathrm{f}_{\mathrm{co}, \mathrm{m}}$ : valor médio da resistência à compressão paralela às fibras;

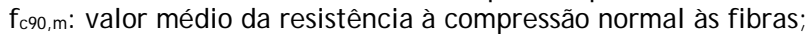

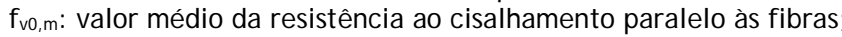

$\mathrm{E}_{c 0, \mathrm{~m}}$ : valor médio do módulo de elasticidade na compressão paralela às fibras;

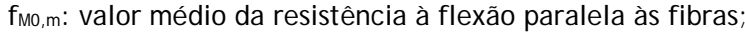

$\mathrm{f}_{\mathrm{t} 0, \mathrm{~m}}$ : valor médio da resistência à tração paralela às fibras;

$\mathrm{E}_{\mathrm{M} 0, \mathrm{~m}}$ : valor médio do módulo de elasticidade na flexão paralela às fibras; e

$\rho_{\mathrm{ap}}$ : valor médio da densidade aparente.

\section{Estrutura real}

A geometria da gridshell construída em escala real consistiu em um octógono irregular, formado por nove módulos, nomeados como 1, 2 e 3 (Figura 6), com quatro lados principais dispostos paralelamente aos eixos ortogonais e quatro lados menores dispostos a $45^{\circ}$. A malha plana foi deformada para simular o processo construtivo da estrutura, ou seja, a transição da configuração plana para a configuração tridimensional curva. Os lados menores com $45^{\circ}$ corresponderam aos apoios da estrutura, enquanto os lados maiores geraram os quatro arcos de entrada para a área coberta. Na malha quadrangular foram utilizadas ripas duplas (Figura 2) na composição dos elementos de barra. Cada ripa foi confeccionada com seção transversal de $4,5 \mathrm{~cm}$ x 1,5 cm e diferentes comprimentos: $200 \mathrm{~cm}, 250 \mathrm{~cm}, 300 \mathrm{~cm}$ e $330 \mathrm{~cm}$ (Figura 7). Os contraventamentos diagonais foram compostos de ripas simples de mesma seção transversal, mas com comprimentos de $35 \mathrm{~cm}$. Assim, a malha plana foi composta de um total de 216 ripas com seções transversais de 4,5 cm x 1,5 cm, dispostas da seguinte forma: 72 ripas com $330 \mathrm{~cm}$ de comprimento dispostas nos módulos 2 e 3 (sendo 48 no módulo 2 e 24 no módulo 3); 112 ripas com 300 cm nos módulos 1 e 2 (sendo 64 no módulo 1 e 48 no módulo 2); 16 ripas com $250 \mathrm{~cm}$ no modulo 1, além de outras 16 ripas com $200 \mathrm{~cm}$ também no módulo 1. Para os contraventamentos foram utilizadas 284 peças. Na união entre os elementos de madeira foram utilizados 836 parafusos, sendo 528 na estrutura principal e 308 nos contraventamentos. As ripas duplas foram unidas ortogonalmente entre si por parafusos galvanizados de diâmetro 6,35 mm e comprimento $100 \mathrm{~mm}$, com cabeça sextavada e rosca total. A fixação dos contraventamentos diagonais foi feita pelo mesmo tipo de parafuso, porém com comprimentos de $50 \mathrm{~mm}$. Em cada parafuso da estrutura principal foram utilizadas duas arruelas e uma porca. Nas ripas de madeira foram utilizados dois diferentes tipos de furação para permitir o melhor ajuste da estrutura para a configuração deformada. Os furos circulares foram feitos com um diâmetro de 7 $\mathrm{mm}$, enquanto os furos alargados foram confeccionados com comprimento de $40 \mathrm{~mm}$ e espessura de $7 \mathrm{~mm}$ (Figura 7). Para manter a continuidade das peças e proporcionar a união entre os módulos, foram confeccionadas emendas ao longo do comprimento. A furação das extremidades dos elementos de contraventamento diagonais e a fixação na estrutura principal foram realizadas após a obtenção da forma curva da gridshell. Essa estratégia visou proporcionar o travamento global da estrutura, evitando-se assim que recuperasse a forma plana durante o processo de montagem, quando da retirada das forças nas diagonais. Vale lembrar também que com a malha disposta horizontalmente na forma plana, antes do processo de curvatura, as diagonais de $45^{\circ}$, opostas entre si, apresentavam dimensões de 10,61 m, enquanto o vão de cada arco de entrada era de 6,50 m. A Figura 6 mostra a planta da gridshell construída, com os detalhes de cada um dos módulos. A Figura 7 mostra os detalhes dos elementos e os respectivos tipos de furação considerados em cada caso.

\section{Etapas de montagem da estrutura principal}

A montagem dos módulos planos de madeira foi feita de forma independente em laboratório. Nesta fase, os parafusos foram mantidos frouxos para permitir o fechamento dos módulos, facilitando o transporte até o local da construção, conforme a Figura 8. Essa opção também teve o objetivo de permitir a rotação relativa entre as ripas ortogonais duplas durante a deformação da malha plana até a obtenção da forma curva. Os parafusos foram inseridos nas emendas comuns entre os módulos como também nos nós da estrutura principal com as cabeças voltadas para o lado convexo (externo) e as porcas para o lado côncavo (interno). 
Figura 6 - Configuração geométrica da gridshell em escala real

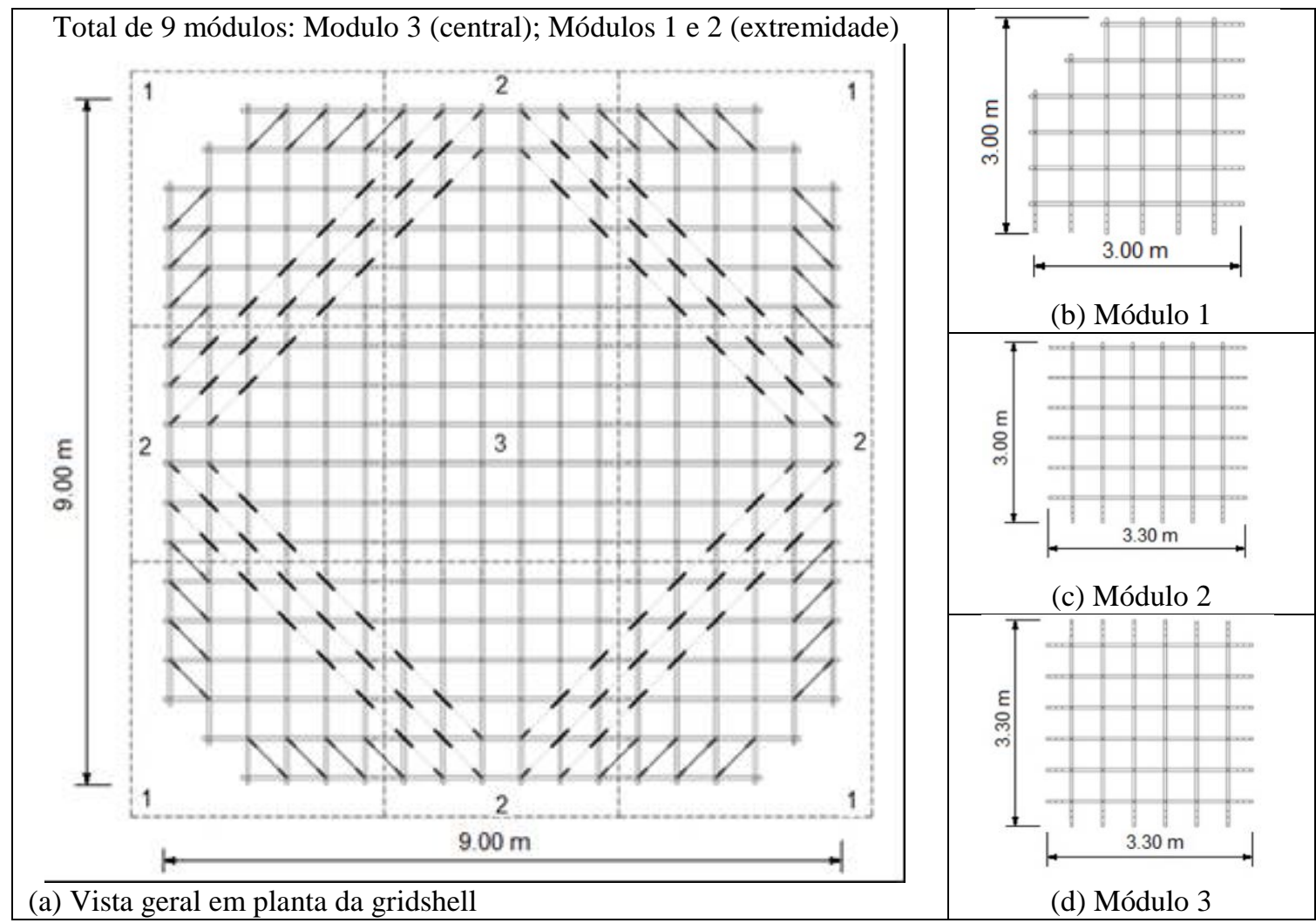

Fonte: modificado de D'Angelo (2011).

Figura 7 - Dimensões das peças e gabaritos de furação (circular e alargado)

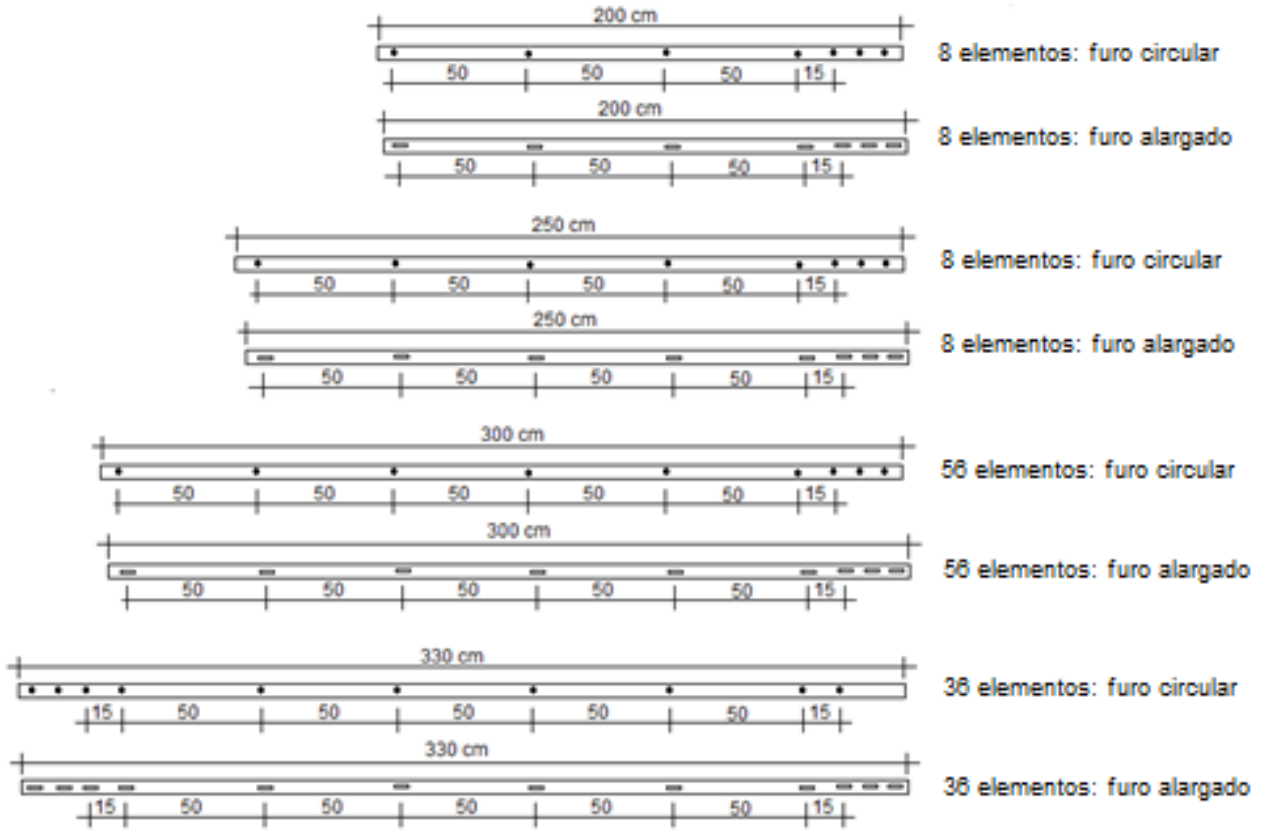

Fonte: modificado de D’Angelo (2011). 
Figura 8 - Etapas de montagem da estrutura real

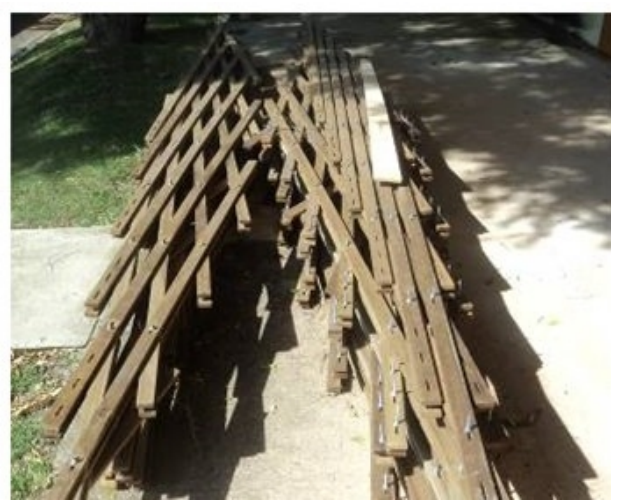

(a) Módulos prontos para transporte

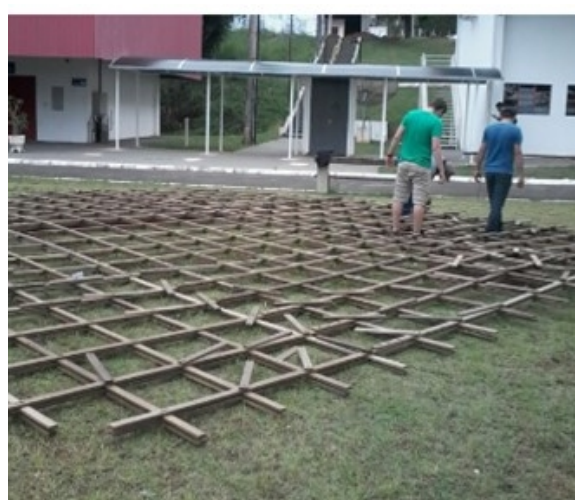

(b) Malha plana completa no local de construção

\section{Curvatura da malha plana}

Uma avaliação inicial com base no modelo reduzido e também nas Equações 5 e 6 mostrou ser possível a obtenção de alturas aproximadas de 2,20 m para cada arco de entrada e de 3,4 m no ponto central mais alto da estrutura. Nessa configuração deformada curva, a malha plana, que inicialmente ocupava uma área de $9 \mathrm{~m} \mathrm{x}$ $9 \mathrm{~m}$, ocuparia uma área de $7 \mathrm{~m} \mathrm{x} 7 \mathrm{~m}$. No entanto, optou-se pela cobertura de uma área maior, a partir da utilização de uma curvatura menor para a malha plana. Assim, as diagonais foram tensionadas até atingirem dimensões horizontais de 9,30 m para a configuração curva. A altura vertical obtida pelo ponto central mais alto da estrutura neste caso foi igual a 2,18 m com a estrutura posicionada no solo. A aplicação da força horizontal nas diagonais dos lados menores para dentro da estrutura foi feita com o auxílio de uma chapa metálica com espessura de 7,94 mm acoplada a 4 polias, sendo esse conjunto posicionado na parte central interna da gridshell. Em cada polia utilizou-se um segmento de corda para puxar a estrutura até atingir a curvatura correspondente à altura de 2,18 m para o arco central. A tração das diagonais dos lados menores ocorreu simultaneamente ao içamento vertical da parte central da gridshell, com o auxílio de um trator munck. A força estimada para o içamento da gridshell foi de $5 \mathrm{KN}$ (500 kgf), sendo esta equivalente ao seu peso próprio de $59 \mathrm{~N} / \mathrm{m}^{2}$. O tensionamento horizontal das diagonais ocorreu em três diferentes etapas (dias). Foi feito o acompanhamento da diminuição das dimensões dos vãos dos arcos de entrada em função do aumento das suas alturas à medida que a estrutura foi sendo curvada. O travamento horizontal da estrutura após cada etapa de tensionamento foi realizado com o auxílio de cordas presas às diagonais e também por estacas de madeira com comprimentos de $25 \mathrm{~cm}$, cravadas no solo, nas quatro bases de apoio. Para diminuir os riscos de ruptura nas regiões mais solicitadas dos arcos de entrada, durante a deformação da estrutura, e se obter uma curvatura mais regular para os arcos, foram utilizados elementos de madeira serrada como apoios, posicionados nos terços dos vãos dos arcos de entrada. Foram utilizados também elementos de madeira (de mesma seção transversal que as ripas duplas da estrutura principal com comprimentos adequados aos trechos de interesse) para reforço nas ligações e nos locais mais sensíveis e com tendências de rupturas. Os elementos de reforço, neste caso, foram fixados na estrutura principal com o auxílio de sargentos e posteriormente parafusados. Enquanto a estrutura permaneceu em repouso durante uma etapa de tensionamento e outra, foi feito o umedecimento da madeira com o uso de aspersores e mangueiras, visando aumentar a flexibilidade da madeira na flexão. Após finalizada as três etapas de tensionamento, a gridshell foi contraventada por elementos diagonais de madeira. A furação das extremidades dos elementos de contraventamento foi ajustada no momento em que estes foram fixados na estrutura principal curvada. Antes do içamento e da colocação da estrutura sobre colunas roliças de eucalipto, os quatro arcos de entrada apresentavam uma altura média de 1,56 m, medida a partir do solo, e um vão correspondente médio de 5,34 m. A Tabela 2 apresenta as etapas de tensionamento da gridshell (Figura 9) até a obtenção da forma curva. As Equações 5 e 6 foram utilizadas para a estimar os raios de curvatura (R) dos arcos centrais e de entrada.

\section{Posicionamento da estrutura principal sobre colunas de apoio}

O içamento da gridshell para o posicionamento sobre um total de doze colunas roliças de madeira de Corymbia citriodora (Figura 10a) foi feito com o auxílio de um caminhão munck. Após o posicionamento da gridshell sobre as colunas (altura média de $84 \mathrm{~cm}$ com relação ao solo), foram iniciadas as leituras das movimentações 
horizontais e verticais para o acompanhamento da acomodação do sistema, por um período total de 19 meses. Na Figura 10b estão apresentados os parâmetros (D - diagonal, L e h - vão e altura do arco de entrada, S suporte de apoio) considerados no acompanhamento da acomodação da estrutura, como também os valores dos desníveis do terreno com relação ao topo das colunas. Na Tabela 3 estão apresentados os valores obtidos em campo para a acomodação da estrutura com base na Figura 10b. Os arcos nomeados na Tabela 3 foram identificados por cores (amarelo, azul, vermelho e laranja), correspondentes aos prédios localizados nas suas proximidades.

A partir da análise da Tabela 3, observou-se que a parte central mais alta da gridshell foi a que sofreu os maiores deslocamentos verticais ao longo do tempo em função da ação do peso próprio da madeira. O deslocamento vertical, neste caso, foi de aproximadamente $20 \mathrm{~cm}$. Para os 4 arcos de entrada, os deslocamentos médios, vertical do topo, como também horizontal de abertura na direção do vão, foram da ordem de $3,75 \mathrm{~cm}$.

Tabela 2 - Valores médios das dimensões da gridshell (no solo) durante o tensionamento

\begin{tabular}{c|c|c|c|c|c|c}
\hline Data & $\mathbf{D}(\mathbf{m})$ & $\mathbf{H}(\mathbf{m})$ & $\mathbf{R}_{\mathbf{d}}(\mathbf{m})$ & $\mathbf{h} \mathbf{( m )}$ & $\mathbf{L}_{\mathbf{m}} \mathbf{( m )}$ & $\mathbf{R}_{\mathbf{a}} \mathbf{( m )}$ \\
\hline $20 / 03 / 2017$ & 10,61 & 0 & - & 0 & 6,50 & - \\
$23 / 03 / 2017$ & 10,17 & 1,42 & 9,81 & 0,60 & 6,45 & 8,97 \\
$28 / 03 / 2017$ & 9,37 & 2,00 & 6,46 & 1,45 & 5,65 & 3,48 \\
$05 / 04 / 2017$ & 9,32 & 2,18 & 6,07 & 1,56 & 5,34 & 3,06 \\
\hline
\end{tabular}

Nota: Legenda:

$\mathrm{D}=$ comprimento da diagonal;

$\mathrm{H}=$ altura do arco central;

$\mathrm{Rd}=$ raio de curvatura para o arco da diagonal;

$\mathrm{h}=$ altura do arco de entrada;

$L_{m}=$ vão do arco de entrada; e

$\mathrm{Ra}=$ raio de curvatura para 0 arco de entrada.

Figura 9 - Etapas de deformação da malha plana para obtenção da forma curvada

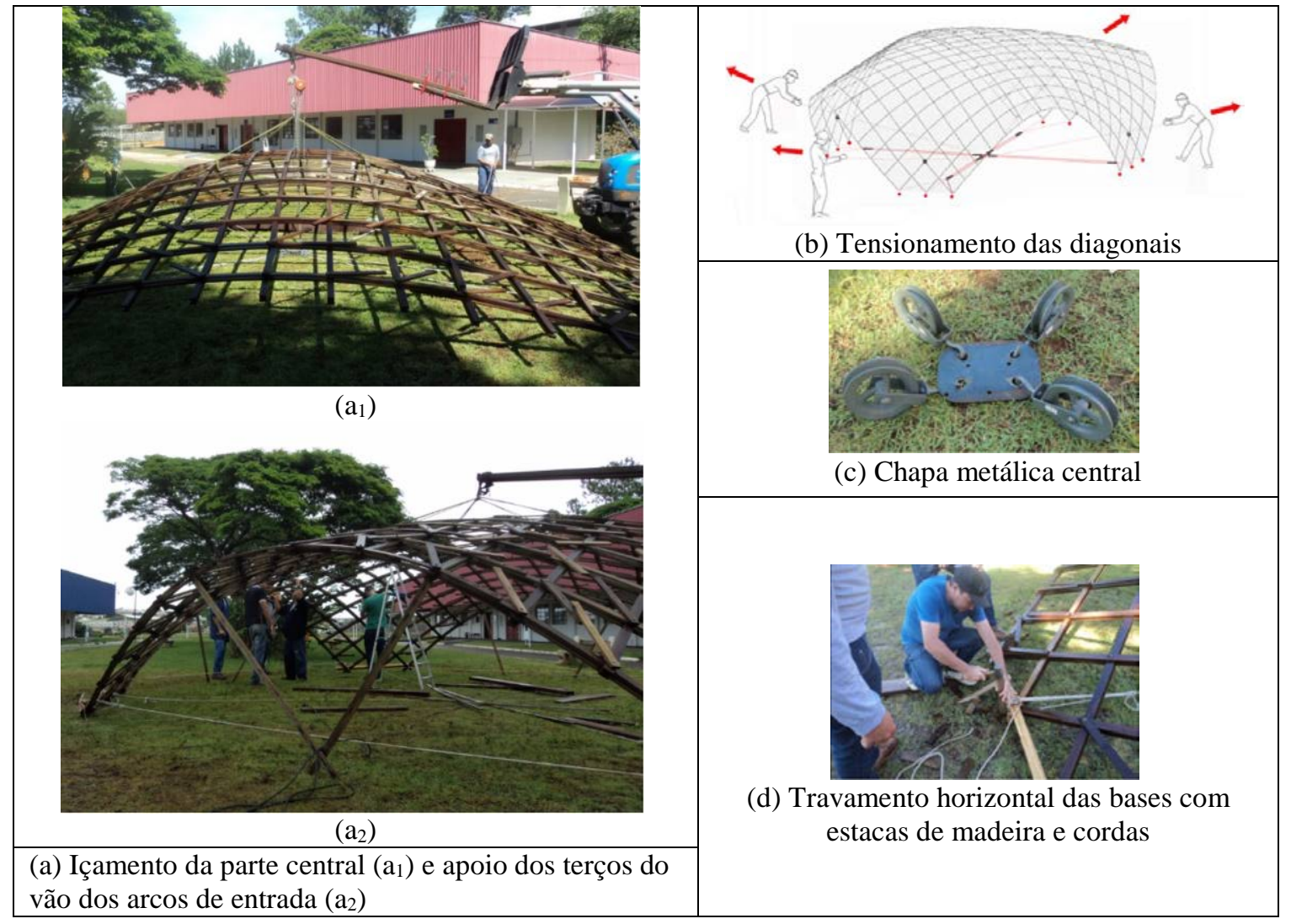

Fonte: (b) D'Angelo (2011). 
Figura 10 - Gridshell sobre colunas: (a) Medida das deflexões com réguas verticais de madeira; (b) Parâmetros para acompanhamento da acomodação da estrutura (Tabela 3)

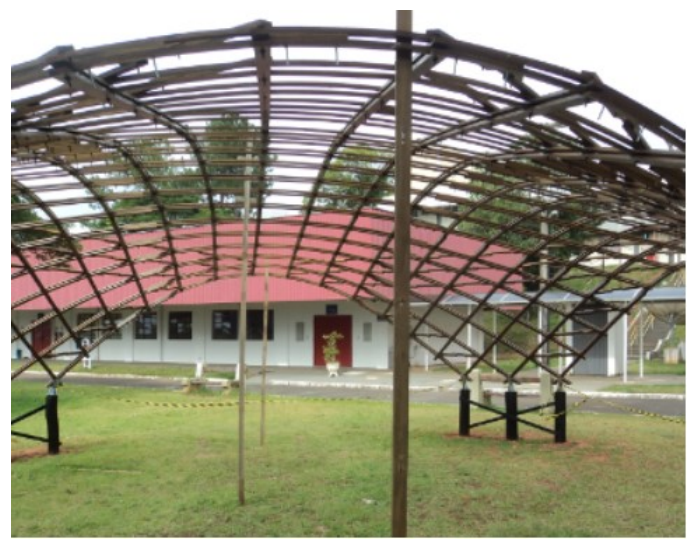

(a)

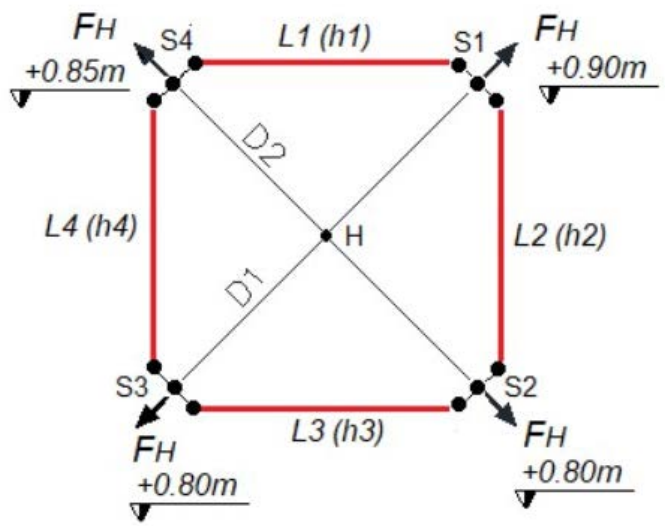

(b)

Tabela 3 - Acompanhamento da acomodação da estrutura (com base na Figura 10b)

\begin{tabular}{|c|c|c|c|c|c|c|c|c|c|c|c|}
\hline \multirow{3}{*}{$\begin{array}{l}\text { Data da } \\
\text { medição }\end{array}$} & \multicolumn{11}{|c|}{ Medidas horizontais e verticais in loco } \\
\hline & \multicolumn{3}{|c|}{ Arcos centrais } & \multicolumn{2}{|c|}{$\begin{array}{c}\text { Arco de } \\
\text { entrada } 1 \\
\text { (Amarelo) }\end{array}$} & \multicolumn{2}{|c|}{$\begin{array}{c}\text { Arco de } \\
\text { entrada } 2 \\
\text { (Azul) } \\
\end{array}$} & \multicolumn{2}{|c|}{$\begin{array}{c}\text { Arco de } \\
\text { entrada } 3 \\
\text { (Vermelho) }\end{array}$} & \multicolumn{2}{|c|}{$\begin{array}{c}\text { Arco de } \\
\text { entrada } 4 \\
\text { (Laranja) }\end{array}$} \\
\hline & $\begin{array}{c}\text { D1 } \\
\text { (m) }\end{array}$ & $\begin{array}{l}\text { D2 } \\
(\mathbf{m})\end{array}$ & $\begin{array}{c}\mathbf{H} \\
(\mathbf{m})\end{array}$ & $\begin{array}{c}\mathbf{L 1} \\
\text { (m) }\end{array}$ & $\begin{array}{c}\text { h1 } \\
\text { (cm) }\end{array}$ & $\begin{array}{c}\mathbf{L} 2 \\
\text { (m) }\end{array}$ & $\begin{array}{c}\mathrm{h} 2 \\
(\mathrm{~cm})\end{array}$ & $\begin{array}{r}\text { L3 } \\
\text { (m) }\end{array}$ & $\begin{array}{c}\text { h3 } \\
\text { (cm) }\end{array}$ & $\begin{array}{r}\text { L4 } \\
\text { (m) }\end{array}$ & $\begin{array}{c}\text { h4 } \\
\text { (cm) }\end{array}$ \\
\hline $05 / 04 / 2017^{*}$ & 9,37 & 9,26 & 2,18 & 5,33 & 1,56 & 5,42 & 1,51 & 5,33 & 1,60 & 5,30 & 1,55 \\
\hline $05 / 05 / 2017^{* *}$ & 9,20 & 9,20 & 2,94 & 5,38 & 2,49 & 5,38 & 2,57 & 5,51 & 2,43 & 5,44 & 2,38 \\
\hline $27 / 02 / 2018^{* *}$ & 9,20 & 9,20 & 2,85 & 5,39 & 2,46 & 5,39 & 2,56 & 5,52 & 2,40 & 5,45 & 2,36 \\
\hline $22 / 03 / 2018^{* *}$ & 9,21 & 9,20 & 2,84 & 5,40 & 2,46 & 5,41 & 2,54 & 5,53 & 2,40 & 5,46 & 2,35 \\
\hline 05/07/2018** & 9,21 & 9,21 & 2,80 & 5,42 & 2,46 & 5,42 & 2,54 & 5,54 & 2,39 & 5,47 & 2,35 \\
\hline 09/08/2018 & 9,21 & 9,21 & 2,80 & 5,42 & 2,46 & 5,42 & 2,54 & 5,54 & 2,39 & 5,47 & 2,35 \\
\hline $01 / 12 / 2018^{* *}$ & 9,22 & 9,22 & 2,75 & 5,42 & 2,45 & 5,42 & 2,53 & 5,54 & 2,39 & 5,47 & 2,34 \\
\hline
\end{tabular}

Nota: *medidas para a gridshell ainda posicionada no solo (Complementa a Tabela 2); e **medidas para a gridshell sobre as 12 colunas roliças.

Quando comparada com o modelo reduzido, a estrutura real apresentou maiores deslocamentos, indicando que o fator volume teve influência significativa neste caso.

Pode-se dizer também, no que se refere à acomodação da estrutura, que, como a forma curva pretendida para a gridshell não foi igual à forma de equilíbrio natural, a estrutura se deslocou para a posição de equilíbrio (posição na qual a estrutura se estabiliza em função da contenção dos deslocamentos horizontais das bases de apoio e consequentemente do topo do arco central), quando da retirada dos suportes de apoio usados internamente para mantê-la sobre as colunas roliças. Na Tabela 4 estão apresentados os deslocamentos horizontais dos topos das colunas roliças ocorridos em função da componente horizontal da força peso $\left(\mathrm{F}_{\mathrm{H}}\right)$, conforme Figura 10b.

Os maiores deslocamentos horizontais ocorridos durante a acomodação da estrutura foram observados na direção da diagonal D1, que liga o suporte de apoio S1 (composto de três colunas roliças) ao suporte S3 (também composto de três colunas roliças).

O suporte de apoio S1 foi o que apresentou maior movimentação horizontal em valor absoluto. No entanto, o valor médio do deslocamento máximo horizontal considerando ambas as diagonais D1 e D2 foi de aproximadamente $1 \mathrm{~cm}$ e este deslocamento foi observado no momento em que a estrutura principal foi posicionada sobre as colunas. Nesse caso, a dimensão inicial das diagonais que era de 9,20 m passou a apresentar 9,21 m após a acomodação completa do sistema. 
Tabela 4 - Prumos das colunas em função da ação das forças horizontais $\mathbf{F}_{\mathbf{H}}$ (Figura 10b)

\begin{tabular}{c|c|c|c|c|c|c}
\hline Data & $\begin{array}{c}\text { S1 } \\
(\mathbf{c m})\end{array}$ & $\begin{array}{c}\text { S2 } \\
(\mathbf{c m})\end{array}$ & $\begin{array}{c}\text { S3 } \\
(\mathbf{c m})\end{array}$ & $\begin{array}{c}\text { S4 } \\
(\mathbf{c m})\end{array}$ & $\begin{array}{c}\Delta \text { S1-S3 } \\
(\mathbf{c m})^{*}\end{array}$ & $\begin{array}{c}\Delta \text { S2-S4 } \\
(\mathbf{c m})^{* *}\end{array}$ \\
\hline $05 / 05 / 2017$ & 0 & 0 & 0 & 0 & 0 & 0 \\
$22 / 03 / 2018$ & 0,60 & 0,53 & 0,10 & 0 & 0,70 & 0,53 \\
$05 / 07 / 2018$ & 0,80 & 0,60 & 0,20 & 0,40 & 1,00 & 1,00 \\
\hline
\end{tabular}

Nota: *variação média da dimensão da diagonal D1 entre os suportes de apoio S1 e S3; e **variação média da dimensão da diagonal D2 entre os suportes de apoio S2 e S4.

Uma vez estabilizados os deslocamentos (horizontais e verticais) da estrutura, procedeu-se ao reaperto dos parafusos da gridshell como também o reforço das bases das colunas para impedir as movimentações horizontais.

\section{Detalhes do sistema de apoio e travamento horizontal}

Cada uma das bases de apoio dos lados menores com $45^{\circ}$ foi composta de três colunas roliças de Corymbia citriodora, com diâmetros aproximados de $16 \mathrm{~cm}$, e comprimentos totais de 1,70 m, totalizando assim 12 colunas de apoio.

As colunas tiveram os movimentos de translação impedidos na direção da componente horizontal $\left(\mathrm{F}_{\mathrm{h}}\right)$ da força F (gerada pela componente do peso próprio da estrutura para um ângulo de 70², Figura 10b).

O impedimento da translação horizontal, neste caso, foi feito por duas peças roliças menores de eucalipto, com diâmetros de $10 \mathrm{~cm}$ e $60 \mathrm{~cm}$ de comprimento (Figura 11b), colocadas transversalmente com relação à direção vertical das colunas. Todo o solo ao redor de cada uma das colunas verticais e sobre as peças roliças transversais foi devidamente compactado para garantir a rigidez necessária para impedir as movimentações horizontais.

Sobre cada uma das colunas de eucalipto foi utilizada uma base metálica com dois parafusos verticais de espera (Figura 11c) para recebimento da estrutura principal.

Para impedir o fendilhamento no topo das colunas de eucalipto foram utilizadas cintas metálicas. O sistema de apoio da gridshell está mostrado na Figura 11.

As forças horizontais $\left(F_{h}\right)$, verticais $\left(F_{v}\right)$ e inclinadas $(F)$, indicadas na Figura 11a, para cada uma das colunas foram $0,15 \mathrm{kN}, 0,42 \mathrm{kN}$ e $0,44 \mathrm{kN}$, respectivamente.

A vinculação da gridshell ao topo das colunas roliças foi realizada por meio de apoios metálicos articuláveis projetados para tal finalidade (Figura 12b) e colocados sobre os parafusos de espera (Figura 11c).

O apoio articulável (Figura 12b) impede as translações horizontal e vertical, e permite o giro, simulando uma rótula.

Em função do desnível do terreno (Figura 10b), foi necessário o nivelamento das alturas dos topos das colunas para receber as bases metálicas articuláveis, como também correções da verticalidade (prumo) das colunas (Figura 12a).

Todas as bases de apoio (conjunto de três colunas) foram contraventadas em X (Figura 10a) por meio do uso de peças serradas (com dimensões de $3 \mathrm{~cm}$ x $5 \mathrm{~cm}$ x $155 \mathrm{~cm}$ ) tendo-se em vista o travamento global da estrutura (giro).

As alturas finais de cada uma das bases de apoio (conjunto de três colunas), após o nivelamento, foram: 90 cm, $85 \mathrm{~cm}, 85 \mathrm{~cm}$ e $80 \mathrm{~cm}$ (Figura 10b).

Ao redor de cada base de apoio foram construídas floreiras pregadas de madeira (Eucaliptus grandis) (Figura 12d), as quais foram posteriormente preenchidas com pedra do tipo brita 1. Utilizou-se, na confecção das floreiras, pregos anelados do tipo 3,10 x $90 \mathrm{~A}$.

Todas as floreiras tiveram reforços internos feitos com peças serradas verticais de madeira para conter as ações horizontais oriundas do peso próprio das britas de preenchimento.

As dimensões internas de cada floreira foram de $72 \mathrm{~cm}$ x $212 \mathrm{~cm}$. As floreiras foram confeccionadas com alturas variáveis acompanhando o nivelamento das bases de apoio em função do desnivelamento do terreno. 


\section{Figura 11 - Sistema de apoio com colunas roliças de Corymbia citriodora}

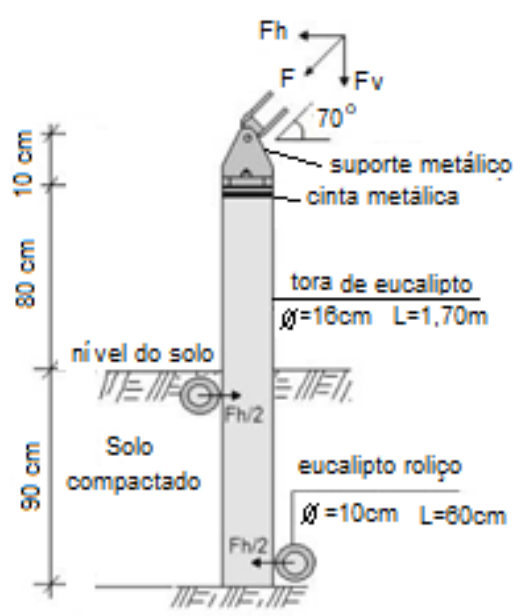

(a) Esquema geral

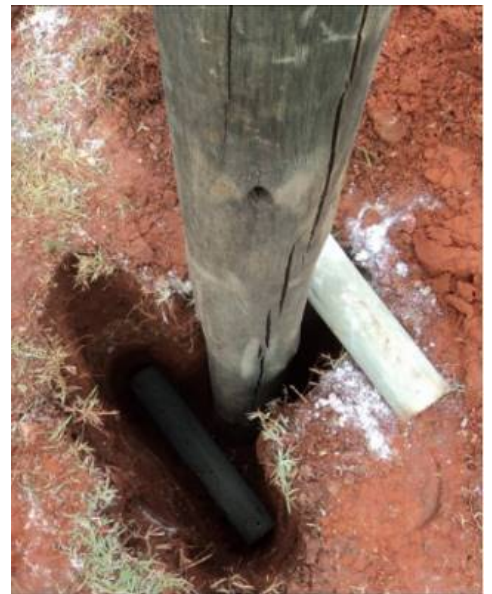

(b) Travamento na direção da força horizontal $\mathrm{F}_{\mathrm{h}}$

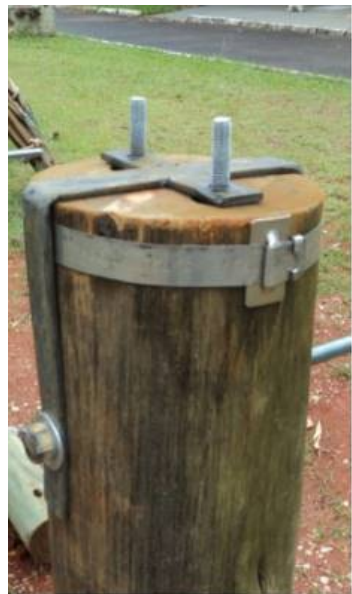

(c) Base metálica de espera

As peças serradas de madeira, componentes das floreiras, tiveram dimensões de $5 \mathrm{~cm}$ x $5 \mathrm{~cm}$ x $82 \mathrm{~cm}$ (direção da largura da floreira) e 5 cm x 5 cm x 222 cm (direção do comprimento).

As superfícies superiores das últimas camadas das peças serradas de madeira das floreiras foram revestidas por calhas metálicas com pingadeiras para impedimento do acúmulo de umidade.

A Figura 12 mostra os principais detalhes das bases de apoio utilizadas para a gridshell com o respectivo acabamento.

\section{Tratamento preservante das madeiras e dos metais}

Todas as madeiras utilizadas na gridshell foram tratadas quimicamente em autoclave com arseniato de cobre cromatado (CCA). Posteriormente, verificou-se, a partir da aplicação de cromo-azurol-S às peças de madeira tratadas com CCA, a profundidade de penetração do tratamento químico. As regiões de alburno com impregnação do tratamento foram identificadas por uma coloração azul intensa. Dessa forma, observou-se que a parte tratável das madeiras receberam o produto preservante. Posteriormente, as madeiras da gridshell como também as regiões externas das floreiras receberam pintura com Stain (cor gold), da marca Osmocolor, através de pincelamento superficial. O produto foi aplicado quando não havia mais a necessidade de umedecimento da madeira, ou seja, após a obtenção da curvatura desejada.

Todos os elementos roliços de madeira como também as partes internas das floreiras receberam pintura por pincelamento com Neutrol.

Os apoios articuláveis como também as demais partes metálicas da estrutura receberam proteção contra corrosão por galvanização a fogo.

Para fins decorativos e de integração social, em cada floreira foram posicionados dois bancos com laterais de concreto e assentos e encostos de madeira, os quais foram pintados com produto Stain na cor imbuia e tinta acrílica na cor mogno, respectivamente.

No interior de cada uma das floreiras foram posicionados refletores para a iluminação noturna. A gridshell, após a conclusão de todos os serviços, está apresentada na Figura 13.

Optou-se por não se utilizar nenhum material de cobertura (por exemplo, telhas de policarbonato) na estrutura principal devido à forte atuação de ventos na região e também para destacar a arquitetura obtida com a forma final curva da estrutura.

\section{Custos envolvidos}

A Tabela 5 apresenta um resumo dos custos envolvidos na construção da gridshell. Foram relacionados os principais materiais, acessórios de acabamento e os serviços envolvidos. Os valores foram apresentados em dólar americano (USD) e em real brasileiro (R\$). A cotação feita considerou um dólar americano custando quatro reais. O custo total estimado por metro quadrado de estrutura construída, neste caso, foi de R $\$ 142 / \mathrm{m}^{2}$ (ou USD 35/ $\mathrm{m}^{2}$ ). 
Figura 12 - Detalhes do sistema de apoio

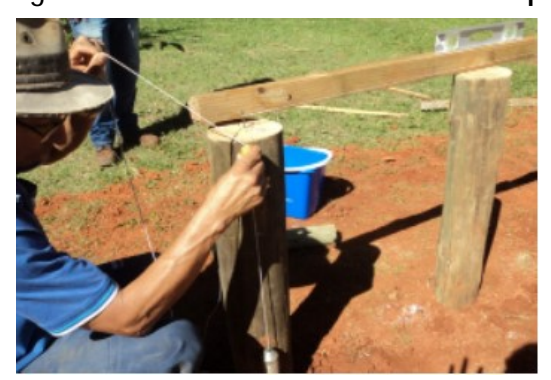

(a) Nivelamento das colunas

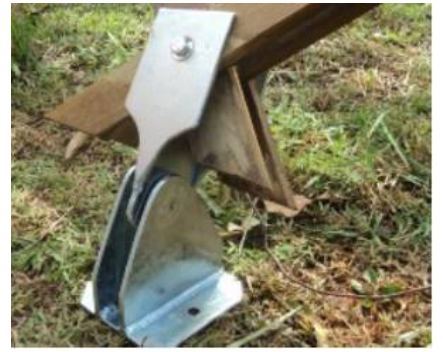

(b) Apoio metálico articulável

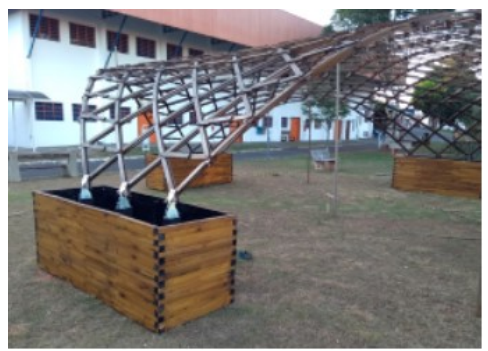

(c) Floreira ao redor das colunas para acabamento

Figura 13 - Gridshell concluída

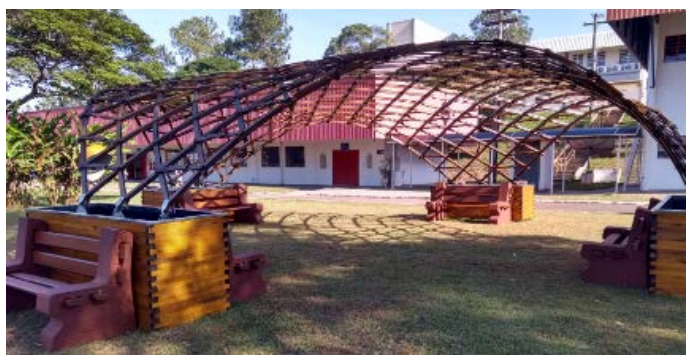

(a) Vista geral diurna

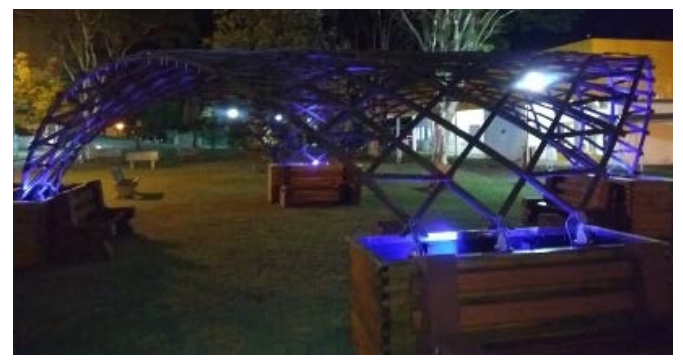

(b) Vista noturna

Tabela 5 - Custos envolvidos, gridshell com dimensões de 9,20 m x 9,20 m

\begin{tabular}{l|c|c|c}
\hline \multicolumn{1}{c|}{ Material/serviço } & Quantidade & $\begin{array}{c}\text { Preço } \\
\text { (R\$) }\end{array}$ & $\begin{array}{c}\text { Preço } \\
\text { (USD) }\end{array}$ \\
\hline Madeira serrada in natura (estrutura principal) & $0,51 \mathrm{~m}^{3}$ & 663 & 165,75 \\
Colunas roliças de Corymbia citriodora & $0,41 \mathrm{~m}^{3}$ & 357 & 89,25 \\
Peças roliças de menor diâmetro (travamento) & $0,12 \mathrm{~m}^{3}$ & 105 & 26,25 \\
Madeira serrada (contraventamento x) & $0,02 \mathrm{~m}^{3}$ & 26 & 6,50 \\
Madeira serrada (floreiras) & $1,07 \mathrm{~m}^{3}$ & 1391 & 347,75 \\
Calha metálica com pingadeira & $25,00 \mathrm{~m}$ & 600 & 150,00 \\
Apoios articuláveis (galvanizados) & $12,00 \mathrm{un}$. & 1435 & 358,75 \\
Suporte metálico de espera & $12 \mathrm{un}$. & 450 & 112,50 \\
Tinta Neutrol & $18 \mathrm{l}$ & 80 & 20,00 \\
Produto Stain (cor gold) & $7,20 \mathrm{l}$ & 680 & 170,00 \\
Produto Stain (cor imbuia) & $3,60 \mathrm{l}$ & 192 & 48,00 \\
Tinta acrílica fosca (mogno) & $3,60 \mathrm{l}$ & 127 & 31,75 \\
Abraçadeiras metálicas & $12,00 \mathrm{un}$. & 300 & 75,00 \\
Caminhão munck & $1 \mathrm{~h}$ & 130 & 32,50 \\
Água (umedecimento da estrutura) & $54,00 \mathrm{~m}^{3}$ & 700 & 175,00 \\
Parafusos com porca e arruela & $836,00 \mathrm{un}$. & 200 & 50,00 \\
Prego anelado & $1 \mathrm{cx}^{2}$ & 300 & 75,00 \\
Serviço de mão de obra & $5 \mathrm{~d}$ & 1500 & 375,00 \\
Tratamento da madeira com CCA & $2,13 \mathrm{~m}^{3}$ & 639 & 159,75 \\
Refletores & $4 \mathrm{un} .^{3}$ & 160 & 40,00 \\
Brita & $5,00 \mathrm{~m}^{3}$ & 350 & 87,50 \\
Bancos & $4 \mathrm{un}$. & 1600 & 400,00 \\
Total & - & 11985 & 2996,25 \\
\hline
\end{tabular}

Nota: Legenda:

$$
\begin{aligned}
& \text { l = litros; } \\
& \text { un. =unidade; } \\
& \text { h=horas; } \\
& \text { cx. = caixa; e } \\
& \text { d = dias. }
\end{aligned}
$$




\section{Considerações finais}

Neste manuscrito, os principais aspectos teóricos e construtivos de uma gridshell em madeira (post-formed) foram descritos. Do ponto de vista teórico, pode-se dizer que o comportamento da gridshell pode ser aproximado ao comportamento de uma estrutura de casca. Esse fato configura um uso eficiente da madeira no que se refere ao tamanho do vão, o que contribui para um menor consumo de material.

Os elementos de barra da gridshell são basicamente sujeitos a esforços de flexão em duas direções, torção e cisalhamento em duas direções. No entanto, não existe um método analítico de cálculo específico para considerar a atuação simultânea dessas ações na estrutura. Nesse caso, são utilizados os critérios de combinações existentes propostos no documento normativo Eurocode 5 (EUROPEAN..., 2008).

Em relação à curvatura dos elementos de barra da gridshell é desejável a utilização de madeiras que sejam capazes de proporcionar a curvatura desejada para a estrutura sem quebrar. Isso pode ser traduzido em uma baixa relação $E_{M} / f_{M}$, na qual se associa uma baixa rigidez à flexão à uma elevada resistência à flexão. Nesse sentido, na construção de gridshells, com madeiras do tipo folhosas, são recomendadas classes de resistência para a madeira até C40. Toussaint (2007) demonstra em seu trabalho, nesse caso, que uma maior resistência à flexão implica um momento fletor máximo mais alto, mas o raio mínimo de curvatura não diminui acima da classe resistência C40.

Cuidado especial deve ser tomado ao se deformar a estrutura, pois quando a deflexão não se aproxima da deflexão de equilíbrio natural, em função da dissimetria geométrica da malha curvada, a estrutura irá se desviar para a sua posição de equilíbrio após a remoção dos suportes para sua acomodação. Isso resultará em uma mudança de geometria e, consequentemente, mudança na distribuição das tensões, o que pode ocasionar a ruptura das ripas que compõem a estrutura.

Durante a montagem da estrutura, a combinação de tensionamentos horizontais nas bases de apoio associados ao içamento vertical da parte central proporciona maior curvatura para a malha plana com menor uso de força horizontal.

Durante o processo de deformação da gridshell para obtenção da forma curva, o umedecimento da madeira por uso de aspersores foi fundamental. Por outro lado, acredita-se que o uso de madeiras verdes pode facilitar a curvatura da malha durante a montagem da estrutura, diminuindo assim os riscos de ruptura. No entanto, essa possibilidade ainda deve ser testada em trabalhos futuros.

Pode-se dizer que devido à influência do fator volume de madeira existiram diferenças significativas entre o comportamento do modelo reduzido e a estrutura real, embora os efeitos encontrados tenham sido similares.

É fundamental o uso de contraventamentos diagonais para a garantia da rigidez da estrutura.

\section{Referências}

AGÊNCIA DE COMUNICAÇÃO DA UNIVERSIDADE FEDERAL DO RIO GRANDE DO NORTE.

Inovação: estudante de mestrado em engenharia civil da UFRN desenvolve estrutura inovadora em madeira. Disponível em: https://ufrn.br/imprensa/materias-especiais/21599/estudante-de-mestrado-em-engenhariacivil-da-ufrn-desenvolve-estrutura-inovadora-em-madeira. Acesso em: $1^{\circ} \mathrm{dez} .2018$.

ASSOCIAÇÃO BRASILEIRA DE NORMAS TÉCNICAS. NBR 7190: projeto de estruturas de madeira. Rio de Janeiro, 1997.

BLASS, H. J. et al. (ed). Timber engineering STEP 1: basis of design, material properties, structural components and joints. Centrum Hout, Almere. 1995.

CAFFARELLO, F. M.; MASCIA, N. T.; BASAGLIA, C. D. Análise estrutural de cobertura em gridshell de madeira considerando o efeito do vento. In: ENCONTRO BRASILEIRO DE MADEIRAS E EM ESTRUTURAS DE MADEIRAS, 15., Curitiba, 2016. Anais [...] Curitiba: IBRAMEM, 2016.

CARVALHO, D. F. P. A. Gridshells em madeira: morfologia, aplicabilidade, comportamento estrutural e projeto. Coimbra, 2015. 70 f. Dissertação (Mestrado em Engenharia Civil) - Escola de Engenharia, Universidade de Coimbra, Coimbra, 2015.

CALIL JUNIOR, C. et.al. Estruturas de Madeira. Rio de Janeiro: Elsevier, 2019.

D’AMICO, B. et al. Timber Gridshells: numerical simulations, design and constructions of a full scale structural. Structures Journal, v. 3, p. 227-235, 2015. 
D’ANGELO, P. La tecnologia delle gridshell: sperimentazione di un sistema di copertura automontante. Napoli, 2011. 75 f. Thesis (Dottorato di ricerca in Tecnologia dell'Architettura), Università degli Studi di Napoli “Federico II, Napoli, 2011.

EUROPEAN COMMITTEE FOR STANDARDIZATION. EUROCODE 5: part 1-1: design of timber structures: general rules and rules for buildings. Brussels, 2008.

GHIYASINASAB, M.; LEHOUX, N.; MÉNARD, S. Production phases and market for timber gridshell structures: a State-of-the art review. BioResources, v. 12, p. 9538-9555, 2017.

HARRIS, R. et al. Design and construction of the downland gridshells. Building Research and Information, v. 31, p. 427-454, 2003.

KUNZ, M.; PRAUCHNER, M. B. Uso do sistema estrutural gridshell na criação de formas complexas em estruturas de madeira. Revista de Arquitetura IMED, v. 4, p. 19-25, 2015.

MESNIL, R. Stability of elastic grid shells. Cambridge, 2013. $114 \mathrm{f}$. (Mater of Engineering), Department of Civil and Environmental Engineering, Massachusetts Institute of Technology, Cambridge, 2013.

SAKAI, Y.; OHSAKI, M. Discrete elastic for shape design of gridshells. Engineering Structures, v. 169, p. 55-57, 2018.

SEIFI, H. et al. Design optimization and additive manufacturing of nodes in gridshell structures.

Engineering Structures, v. 160, p. 161-170, 2018.

TEDESCHI, A. Architecture and computational design VAT: IT03127760787. Gridshell form finding experiment with Kangaroo. Disponível em: http://www.arturotedeschi.com/wordpress/?page_id=5467. Acesso em: $1^{\circ}$ dez. 2018.

TOUSSAINT, M. H. A. A design tool for timber gridshells: the development of a grid generation tool. The Netherlands, 2007. 223 f. Thesis (Mater of Science in Civil Engineering), Delft University of Technology, Netherlands, 2007.

YOUNG, W. C.; BUDYNAS, R. G. Roark’s formulas for stress and strain. $7^{\text {th }}$. ed. New York: McGrawHill, 2002.

\section{Agradecimentos}

Á UNESP, campus de Itapeva - SP, por ceder o local para a instalação da estrutura de cobertura apresentada neste projeto. 


\section{J ulio Cesar Molina}

Faculdade de Engenharia Industrial Madeireira | Universidade Estadual Paulista | Rua Geraldo Alckimin, 519, Vila N. Sra de Fátima | Itapeva - SP - Brasil | CEP CEP 18409-010 | Tel.: (15) 3524-9100 | E-mail: julio.molina@unesp.br

\section{Carlito Calil Neto}

Rewood - Soluções Estruturais em Madeira Laminada Colada | Rua Paulino Nunes 127, Parque Industrial das Oliveiras | Taboão da Serra SP - Brasil | CEP 05576-100| Tel.: (11) 4787-3366| E-mail: contato@rewood.com.br

\section{Anderson Diego da Fé}

Departamento de Engenharia Mecânica | Universidade Estadual Paulista | Av. Dr. Ariberto Pereira da Cunha, 333, Portal das Colinas | Guaratinguetá - SP - Brasil | CEP 12516-410 | Tel.: (12) 3123-2814 | E-mail: anderson.diego_07@hotmail.com

\section{Ulysses Martins Freitas}

Faculdade de Engenharia Industrial Madeireira | Universidade Estadual Paulista | E-mail: ulyssesmartinsfreitas@hotmail.com

\section{Pablo Henrique de Morais}

Faculdade de Engenharia Industrial Madeireira | Universidade Estadual Paulista | E-mail: pablo.hmorais@gmail.com

\section{Gabriela da Silva Matos}

Faculdade de Engenharia Industrial Madeireira | Universidade Estadual Paulista | E-mail: matos.gabbi@gmail.com

\section{Ambiente Construído}

Revista da Associação Nacional de Tecnologia do Ambiente Construído

Av. Osvaldo Aranha, 99 - 3o andar, Centro

Porto Alegre - RS - Brasil

$$
\text { CEP } 90035-190
$$

Telefone: +55 (51) 3308-4084

Fax: +55 (51) 3308-4054

www. seer. ufrgs. br/ ambienteconstruido

E-mail: ambienteconstruido@ufrgs.br 